Methods One hundred and thirty-six cancer patients surveyed for an occupational disease of the bladder were investigated for the course of the disease. EDTA blood samples were drawn. Patients were genotyped for the following polymorphisms: N-acetyltransferase 2 (NAT2, substrate: aromatic amines), glutathione S-transferase M1 (GSTM1, substrate: reactive metabolites of $\mathrm{PAH})$, glutathione S-transferase T1 (GSTT1, substrate: small molecules with 1 or 2 carbon atoms), UDP-glucuronyltransferase 1A2 rs11892031 (UGT1A2, substrate: aromatic amines), rs9642880 (close to c-Myc gene) and rs710521 (close to TP63). Frequencies of recurrences were analysed by means of chi-square test, relapse-free times were analysed by unadjusted Cox regression. The combined effect of the polymorphisms was analysed by means of the weighted polygenic risk score (PRS).

Results In $38 \%$ of the patients a recurrence was reported (median 1.54 years). All investigated polymorphisms except for rs710521 showed a tendency to more frequent recurrences and shorter recurrence-free times, in particular NAT2 (slow vs fast: hazard ratio $\mathrm{HR} 1.75,95 \% \mathrm{CI}: 0.98$ to 3.12 , $\mathrm{p}=0.0582$ ), GSTM1 (positive versus negative: HR 1.77, 95\% CI: 0.70 to $4.48, \mathrm{p}=0.2222$ ) and GSTM1 (negative vs positive, HR 1.37, 95\% CI: 0.76 to $2,45, \mathrm{p}=0.2972$ ). The PRS was significantly associated with shorter recurrence-free times (PRS >median vs PRS Smedian score: 18 vs 26 months, $\mathrm{HR}=1.93$, 95\% CI: 1.06 to $3.53 ; \mathrm{p}=0.0327)$, the risk of recurrence was also higher $(47 \%$ vs $31 \%, \mathrm{OR}=1.94,95 \% \mathrm{CI}$ : 0.93 to $4.06, \mathrm{p}=0.0757)$.

Conclusion Polymorphic xenobiotic metabolising enzymes may modulate the prognosis of occupational bladder cancer.

\section{CASE STUDY IN DATA ACCESS AND REANALYSIS: DIESEL ENGINE EXHAUST AND LUNG CANCER MORTALITY IN THE DIESEL EXHAUST IN MINERS STUDY (DEMS) COHORT USING ALTERNATIVE EXPOSURE ESTIMATES AND RADON ADJUSTMENT}

Roger 0 McClellan. Toxicology and Risk Analysis, Albuquerque, New Mexico, USA

\subsection{6/oemed-2018-ICOHabstracts. 1150}

Introduction The Diesel Exhaust in Miners Study (DEMS), conducted by National Institute of Occupational Safety and Health (NIOSH) and National Cancer Institute (NCI), included 12315 workers with 200 observed lung cancers from 8 U.S. non-metal mines ( 3 trona, 3 potash, 1 salt and 1 limestone). Retrospective cohort and case-control analyses by NIOSH and NCI scientists yielded a positive association between diesel exhaust exposure (DEE), represented by a respirable elemental carbon (REC) metric estimated retrospectively from carbon monoxide measurements, and lung cancer mortality. This finding was a major factor in the International Agency for Research on Cancer (IARC) classification of DEE as a human carcinogen.

Methods Our team was given access to the DEMS data and conducted analyses to first replicate the original analyses and then conduct extended re-analyses. Our re-analyses focused on

a. use of an alternative exposure metric developed using historical data on diesel equipment, engine horse power and ventilation rates without dependence on use of carbon monoxide as a surrogate for REC,

b. inclusion of radon as a covariate in statistical models, and

c. subgroup heterogeneity.
Results We found associations with cumulative REC and average REC intensity using the alternative REC estimates were generally attenuated compared with those found using the original DEMS REC estimate. Most findings were statistically nonsignificant, especially after control for radon exposure, which substantially weakened associations with the original and alternative REC estimates. No significant findings were detected among all miners who worked exclusively underground. However, associations were anomalously strong among limestone miners; no association with REC or radon was found among workers at the other seven mines.

Conclusions The large differences in results based on alternative exposure estimates, control for radon, and stratification by worker location or mine type highlight areas of uncertainty and the limited robustness of the DEMS data. These limitations must be considered in any extrapolation of the DEMS findings to other populations, and especially in using them for quantitative risk assessment. Moreover, the recently complete Advanced Collaborative Emissions Study (ACES) study sponsored by the Health Effects Institute and conducted at the Lovelace Respiratory Research Institute, Albuquerque, NM, indicated that chronic inhalation exposure of rats to low dilutions of exhaust from new technology diesel engines did not produce lung cancer. The results of both the DEMS and ACES findings will be reviewed to provide perspective for evaluating the cancer hazards of diesel-powered equipment, past, present and future.

\section{2a EVALUATING EXPOSURE TO DIESEL ENGINE EXHAUST}

JM Berg*. Centre for Toxicology and Environmental Health, LLC; Texas, USA

\subsection{6/oemed-2018-ICOHabstracts.1151}

Introduction Exposure to diesel engine exhaust continues to be a concern for employers who utilise either traditional (TDE) or new technology diesel (NTDE) exhaust-powered equipment. Such exposure may occur at elevated concentrations over a short period of time (acute) or at much lower concentrations on a daily basis over their working lifetime (chronic). Individuals in each of these exposure scenarios may present with different symptomology or health effects. In either case, accurately assessing an individuals exposure to diesel exhaust should be done in the context of appropriate toxicological endpoint of relevance (e.g., irritation, carcinogenicity, etc.).

Methods A review of the toxicological and industrial hygiene literature was conducted to identify historical trends in exposure sampling methodology and analytical surrogate chosen. Additional studies were reviewed which highlighted the important compositional distinctions between TDE and NTDE and also the reported symptomology which presented following acute exposures.

Results Historically, a number of analytical surrogates for diesel exhaust have been utilised to assess exposure including both particulate phase and gaseous compounds. While at the present time, sampling for elemental carbon or respirable elemental carbon (REC) is currently the most utilised surrogate, recent literature indicates that the elemental carbon fractions of TDE and NTDE may substantially differ. Furthermore, a number of studies noted that acute exposure to diesel exhaust may elicit transient irritant or neurophysiological effects 
indicative of exposure to gaseous components (e.g., aldehydes, $\left.\mathrm{NO}_{\mathrm{x}}, \mathrm{SO}_{\mathrm{x}}, \mathrm{CO}\right)$ of diesel exhaust.

Conclusion This study highlights both the historical context and the current status of exposure sampling for diesel exhaust in the occupational setting. Development of exposure sampling plans in the workplace should take into account both the timeframe of exposure (e.g., acute or chronic) and the toxicological endpoints of concern (e.g., acute irritation or chronic ailment). Furthermore, the individual assessing exposure should be aware of, and account for the differences between traditional diesel engine exhaust (TDE) and new technology diesel engine exhaust (NTDE).

\section{$1712 \mathrm{~b}$ OVERVIEW OF DIESEL ENGINE EXHAUST ISSUES}

William B Bunn. Medical University of South Carolina

\subsection{6/oemed-2018-ICOHabstracts.1152}

The mutagenicity of organic solvent extracts of diesel exhaust extracts was first noted over 60 years ago. Epidemiology and toxicology studies have resulted in classification of diesel exhaust by the International Agency for Research on Cancer (IARC) as a known carcinogen and by United States Environmental Protection Agency (USEPA) as likely to cause cancer; however, there is continued debate and quantitative risk has not been established by USEPA or environmental regulatory bodies in other countries. The major changes in diesel exhaust emissions make New Technology Diesel Exhaust (NTDE) distinct from the historic epidemiologic studies and recent animal bioassays question the relevance of studies of traditional diesel exhaust for risk assessment of NTDE.

\section{$1712 \mathrm{C}$ OCCUPATIONAL DIESEL EXHAUST EXPOSURE IN RELATION TO LUNG CANCER AND ISCHAEMIC HEART DISEASE MORTALITY}

Andreas M Neophytou, Sadie Costello, Ellen A Eisen. Environmental Health Sciences, School of Public Health, University of California, Berkeley, Berkeley, California, USA

\subsection{6/oemed-2018-ICOHabstracts. 1153}

Introduction General population studies of air pollution suggest that particles from diesel exhaust emissions are a potential risk factor for cardiovascular disease, while diesel exhaust is also classified as a known human carcinogen. We used data from the Diesel Exhaust in Miners Study to assess excess risk of lung cancer and ischaemic heart disease mortality associated with occupational diesel exhaust exposure.

Methods Analyses were performed in a cohort of non-metal miners in the US $(n=12,315)$, who were exposed to diesel exhaust. We applied the parametric g-formula to assess how hypothetical interventions setting respirable elemental carbon (surrogate for diesel) exposure limits would have impacted lifetime risk of lung cancer, and ischaemic heart disease mortality, while adjusting for time-varying employment status.

Results Lung cancer and ischaemic heart disease mortality risk decreased in association with interventions on respirable elemental carbon, with risk ratios of 0.73 (95\% confidence interval CI: 0.44 to 1.07$)$ and 0.86 (95\% CI: 0.66 to 1.12$)$ respectively, when comparing an intervention setting respirable elemental carbon exposure to zero to the observed natural course.
Conclusion Our findings suggest excess risk of lung cancer and ischaemic heart disease mortality associated with diesel exhaust exposure in this occupational setting and that interventions on exposure would have resulted in reduced risk for both outcomes.

\section{HIGH TEMPERATURE INSULATION WOOLS: STUDY OF CYTOTOXIC, GENOTOXIC/OXIDATIVE AND INFLAMMATORY EFFECTS OF POLYCRYSTALLINE WOOLS COMPARED WITH REFRACTORY CERAMIC FIBRES}

D Cavallo*, CL Ursini, A Campopiano, AM Fresegna, A Ciervo, R Maiello, A Cannizzaro, F Angelosanto, S lavicoli. Department of Occupational and Environmental Medicine, Epidemiology and Hygiene, INAIL - Italian Workers' Compensation Authority, Rome, Italy

\subsection{6/oemed-2018-ICOHabstracts.1154}

Introduction Refractory ceramic fibres (RCF) and polycrystalline wools (PCW) constitute a family of fibres known as High Temperature Insulation Wools used in industrial applications above $800^{\circ} \mathrm{C}$. Current European Classification, Labelling and Packaging of substances and mixtures classifies RCF as Category $1 \mathrm{~B}$ ('Substances presumed to have carcinogenic potential for humans'). Regarding PCW toxicity, no studies are available. We aimed to evaluate and compare cytotoxic, genotoxicoxidative and inflammatory effects of alumina-silicate RCF and PCW on human alveolar (A549) cells.

Methods SEM analysis was performed to characterise fibre dimensions. We exposed for 24 hour the cells to five different concentrations $(2-100 \mu \mathrm{g} / \mathrm{ml})$ of tested fibres to evaluate viability reduction by MTT and Trypan blue assays, membrane damage by LDH release, direct/oxidative DNA damage by Fpg comet assay and IL-6, IL-8 and TNF $\alpha$ cytokine release by ELISA.

Results SEM analysis found a length-weighted geometric mean fibre diameter $\left(\mathrm{D}^{\mathrm{LG}}\right)$ of $2.1 \mu \mathrm{m}$ with $68 \%$ of respirable fibres for RCF and a $\mathrm{D}^{\mathrm{LG}}$ of $4.2 \mu \mathrm{m}$ and $20 \%$ of respirable fibres for PCW. Moreover the content of fibres with $\mathrm{d}<3 \mu \mathrm{m}$ and $1>20 \mu \mathrm{m}$ was $44 \%$ in RCF and $11 \%$ in PCW. We found lack of viability reduction for both fibres and membrane damage induction only for RCF at $100 \mu \mathrm{g} / \mathrm{ml}$. Both the fibres induced dose-dependent DNA damage that, however, was higher for RCF reaching 5.7 fold of control vs 3.8 of PCW. Oxidative effects were induced only by RCF at the lowest concentrations. Regarding inflammatory effects, both the fibres induced only slight increase of IL-6 release at $100 \mu \mathrm{g} / \mathrm{ml}$.

Conclusion The study confirms the genotoxic/oxidative potential of RCF with thinner $\mathrm{D}^{\mathrm{LG}}$, higher percentage of respirable and longer fibres than PCW and shows genotoxicity also for PCW, suggesting also for this fibre with similar chemical composition and low biosolubility, the need of further studies to confirm such results also on other cells.

\section{SPECIFIC BIOMARKERS FOR THE EXPOSURE TO ORGANOPHOSPHATE AND CARBAMATE PESTICIDES}

Thomas Göen*, Heike Denghel, Hans Drexler. Inst. of Occupational, Social and Environmental Medicine, University of Erlangen-Nuremberg, Erlangen, Germany

\subsection{6/oemed-2018-ICOHabstracts.1155}

Introduction Organophosphate pesticides (OPP) and carbamates are still counted among the most prominent agents used for crops protection. Up to date the determination of dialkyl 